\title{
Short-run Economic Assessment of the Transportation Recovery Policy After an Earthquake
}

\author{
Atsushi Koike ${ }^{1, *}$, and Yoshinao Miyamoto ${ }^{1}$ \\ ${ }^{1}$ Kobe University, Department of Civil Engineering, 1-1 Rokkodai-cho, Nada-ku, Kobe-shi, Hyogo \\ 657-8501, Japan
}

\begin{abstract}
This paper develops a short-run economic damage assessment model. The model contains two sub models. One is the conventional traffic assignment model, which calculates traveling time under the damaged transportation infrastructure. The other is the economic damage assessment model, which determines the decrease in production level in the short run. This method facilitates the identification of critical infrastructure that could reduce the economic damage when the disaster occurs. As a case study, we applied this model to several recovery plans for transport facilities. The results suggest that the proposed comprehensive model should be considered as a prevention plan.
\end{abstract}

\section{Introduction}

There is a $70 \%$ possibility that a huge earthquake will hit the Nankai trough in Japan in the next 30 years. Thus, the economic damage assessment of earthquakes is required for effective recovery.

When the Great East Japan Earthquake occurred, there were several types of economic damage: first, "the middle/long-run damage," which is the damage to production facilities or customers; second, "the short-run damage," which is the shortage of labor or intermediate supply by the damage of transportation infrastructure. [1] Since the response just after the disaster influences the economic recovery both temporally and spatially, it might be important to be focused on the short-run damage. In addition, there is a possibility that the spatially uniform policy does not work well in some regions. To sum up, it is assumed that the comprehensive policy, considering the damage factor in each region, should be planned for the effective recovery.

There are many previous studies on the economic damage assessment (e.g., Koike et al. (2014), Tsuchiya et al. (2006) [2,3]). However, they are focused on the middle/long-run effects, while there no studies on the analysis of the short-run effect.

This paper proposes an economic damage assessment model in the short-run. Additionally, the model is applied to the Chukyo metropolitan area, which is predicted to be the most seriously damaged by the Nankai Trough Earthquake. We analyze the

*E-mail address: koike@lion.kobe-u.ac.jp 
economic damage and specify the main factors of damage in each industry of every region. In addition, we simulate two recovery policies on transportation facilities to develop the effective recovery policy.

\section{Structure of the economic damage assessment model in the short-run}

\subsection{Outline of the model}

Fig. 1 shows the whole structure of the economic damage assessment model in the short run. This model contains two sub models, namely the transportation model to calculate traveling time and the economic damage assessment model to determine the decrease in products in the short-run. This model can analyze the factors that affect economic damage the most in each industry in every zone. If the earthquake damages the road or railway network, traveling time increases and it causes the limitation of labor supply, intermediate supply, or production supply. Finally, the decrease in production is determined by the production function with a Leontief technology.

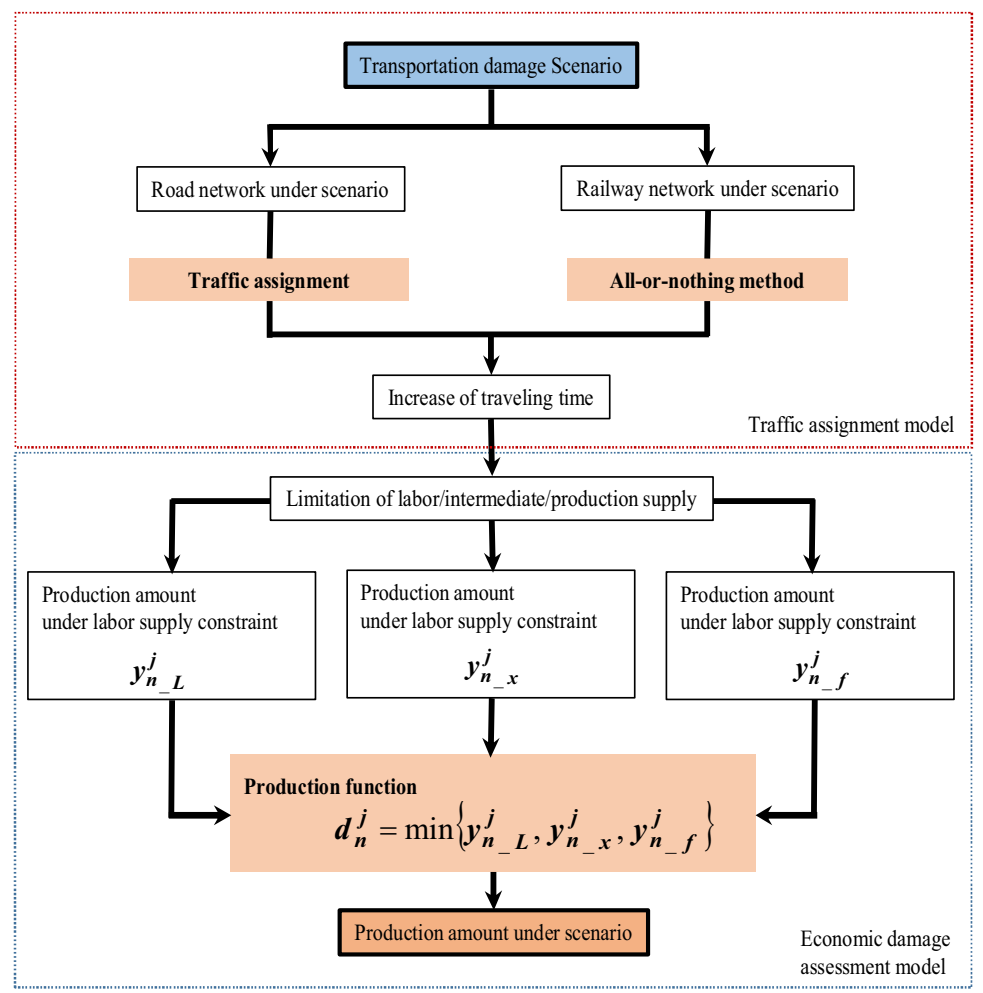

Fig. 1. Structure of the economic damage assessment model in the short-run

\subsection{Transportation model}

In the transportation model, traveling time is calculated by analyzing the traffic assignment using the origin-destination (OD) table and network data. We applied the incremental 
assignment method to the road network. Whereas the all-or-nothing method is applied to the railway network on the ground to ensure there is no congestion.

Generally, the traffic assignment analysis applies the four-step method. However, in this paper, the traffic assignment model is used on the assumption that the trip generation, destination, and modal split are not changed in the short-run. In addition, we apply the incremental assignment to the road network to reduce the calculation load.

\subsection{Economic damage assessment model}

\subsubsection{Production function}

The production amount at zone $j$ of industry $n$ is determined by the following: $y_{n}{ }_{L}^{j}$ means the production amount under constraint wherein only the labor cannot commute and the intermediate or production goods are supplied as usual. This equation shows that the production amount is determined as that under the most seriously damaged factor.

$$
d_{n}^{j}=\min \left\{y_{n_{-} L}^{j}, y_{n_{-} x}^{j}, y_{n_{-} f}^{j}\right\}
$$

where $\mathrm{d}_{\mathrm{n}}^{\mathrm{j}}$ : production amount; $\mathrm{y}_{\mathrm{n}_{-}} \mathrm{L}^{\mathrm{j}}, \mathrm{y}_{\mathrm{n}_{-} \mathrm{x}}{ }^{\mathrm{j}}, \mathrm{y}_{\mathrm{n}_{-}}{ }_{\mathrm{f}}^{\mathrm{j}}$ : production amount under damage factor constraint

The production amounts under the damage factor constraint are described as follows. In this paper, the production functions (Equation (1), (2), and (3)) are all specified with the Leontief technology since it is assumed that production factors in the short-run are not substituted.

$$
\begin{gathered}
y_{n_{-}{ }^{j}{ }^{\prime}}=\frac{L_{j}^{n \prime}}{a_{L n}^{j}} \\
y_{n_{-} x}^{j_{1}}=\min \left\{\frac{x_{1 n}^{j}{ }^{\prime}}{a_{1 n}^{j}}, \frac{x_{2 n}^{j}{ }^{\prime}}{a_{2 n}^{j}}, \ldots, \frac{x_{m n}^{j}{ }^{\prime}}{a_{m n}^{j}}\right\} \\
y_{n_{-}{ }_{f}}^{j,}=u_{j}^{m} \cdot y_{n}^{j}
\end{gathered}
$$

where $\mathrm{L}_{\mathrm{j}}{ }_{\mathrm{j}}$ : labor supply; $\mathrm{a}_{\mathrm{Ln}}{ }^{\mathrm{j}}, \mathrm{a}_{\mathrm{mn}}{ }^{\mathrm{j}}$ : input coefficient; $\mathrm{u}_{\mathrm{j}}{ }^{\mathrm{m}}$ : reduction rate of production amount; (A' means A under the scenario).

\subsubsection{Limitation of labor/intermediate/production supply}

In this paper, we assume that the increase of traveling time influences the working time or decision making of freight transportation. The reduction rate of labor supply $\mathrm{s}_{\mathrm{j}}^{\mathrm{L}}$ is defined as Equation (5) and the amount of labor supply is calculated by Equation (6). Next, we set the working time as 8 hours per day per worker and it is reduced by the increase in traveling time.

$$
s_{j}^{L}=\frac{\sum_{i}\left(8-2 E_{i j}^{c a r}\right) N_{i j}^{c a r}+8 N_{i j}^{p u b},}{\sum_{i} 8 N_{i j}^{c a r}+8 N_{i j}^{p u b}}
$$




$$
L_{j}^{n '}=s_{j}^{L} \cdot L_{j}^{n}
$$

where $\mathrm{N}_{\mathrm{ij}}{ }^{\mathrm{car}}, \mathrm{N}_{\mathrm{ij}}{ }^{\text {pub }}$ : a number of commuting trips; $\mathrm{E}_{\mathrm{ij}}{ }^{\mathrm{car}}$ : increase in traveling time

Moreover, the limitations of freight transportation are determined depending on the increase in the rate of traveling time. It is assumed that the firms decide to stop transport if it takes more than 1.5 times the usual traveling time. The reduction of transported intermediate goods is $\mathrm{I}_{\mathrm{ij}}^{\mathrm{m}}$, and the reduction rate of intermediate supply is calculated by Equation (7). Finally, the amount of intermediate supply under damaged by transportation is determined by Equation (9). Additionally, it is the same for production supply.

$$
\begin{gathered}
t_{j}^{m}=\frac{\sum_{i} I_{i j}^{m \prime}}{\sum_{i} I_{i j}^{m}} \\
u_{j}^{m}=\frac{\sum_{k} F_{j k}^{m}}{\sum_{k} F_{j k}^{m}} \\
x_{m n}^{j}{ }^{\prime}=t_{j}^{m} \cdot x_{m n}^{j}
\end{gathered}
$$

where $\mathrm{I}_{\mathrm{ij}}{ }^{\mathrm{m}}$ : intermediate supply; $\mathrm{F}_{\mathrm{jk}}{ }^{\mathrm{m}}$ : production supply.

\subsection{Data and data sources}

The model requires the following dataset shown in Table 1. In the transportation model, the required network data and velocity data is obtained from the Road Traffic Census. In addition, the OD matrix of commuting and freight transportation is developed by using the Chukyo PT Survey and Chukyo Logistics Survey data. In the economic damage assessment model, a dataset is required to develop the GDP data in each industry in every region. If there are some regions where GDP data is not available, it could be estimated based on the number of workers in that region. The input coefficients of labor and intermediate goods are derived from the Input-Output table.

Table 1. Data sources

\begin{tabular}{|l|l|}
\hline & \multicolumn{1}{|c|}{ Data sources } \\
\hline Road network & $\begin{array}{l}\text { Digital Road Map } \\
\text { Road Traffic Census }\end{array}$ \\
\hline Rail network & National Land Numerical Information \\
\hline Commute OD matrix & Chukyo Urban Area Person Trip Survey \\
\hline Freight OD matrix & Chukyo Urban Area Logistics Survey \\
\hline & GDP Classified by Economic Activities \\
& Economic Census for Business Frame \\
GDP table & Economic Census for Business Activity \\
& Census of Manufactures \\
& Input-Output Table \\
\hline Input coefficient & Input-Output Table \\
\hline
\end{tabular}




\section{Case study}

\subsection{Details on assumptions and scenario setting}

\subsubsection{Coverage area and transport infrastructure}

The coverage area is Chukyo metropolitan area (Aichi Prefecture, the northern part of Mie prefecture and the southern part of Gifu prefecture), which is divided into 111 zones. Fig. 3 and Fig. 4 show the transport infrastructure in the coverage area. We have excluded the local streets and the Shinkansen line.

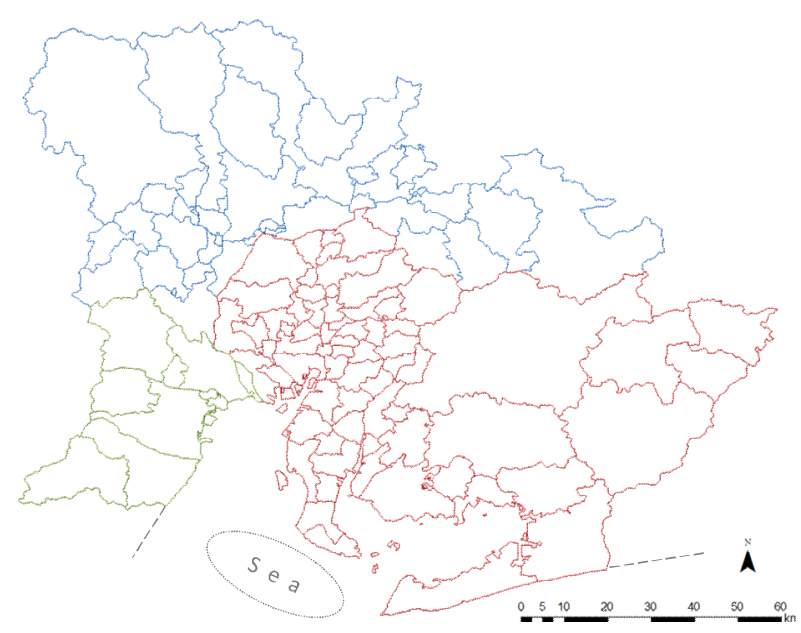

Fig. 2. Coverage area (111 ZONE)

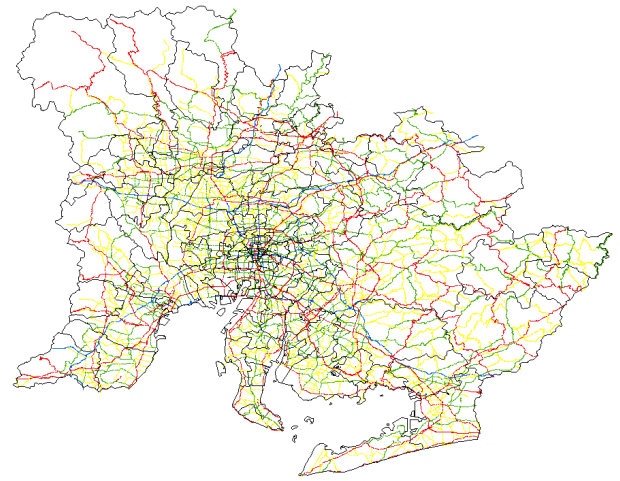

Fig. 3. Road network

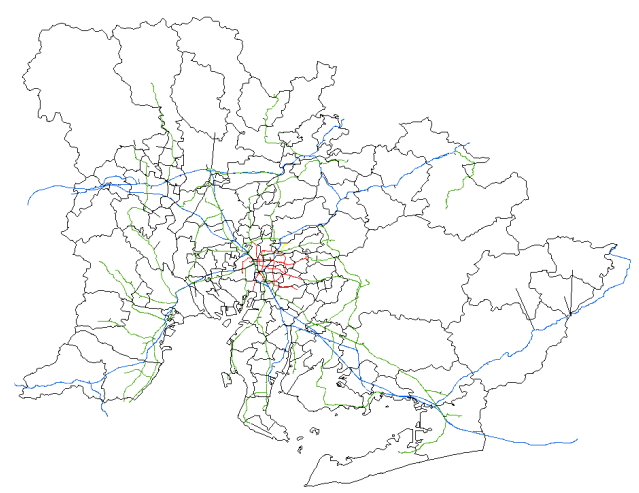

Fig. 4. Railway network

\subsubsection{Setting the scenario}

We applied the model to evaluate the damage of transport infrastructure in the Chukyo metropolitan area. We set the scenario wherein the road network and railway network cannot be used in a flood-assumed area. Fig. 5 shows that the traveling time increases considerably between the regions across the Kiso, Nagara and Ibo rivers. 


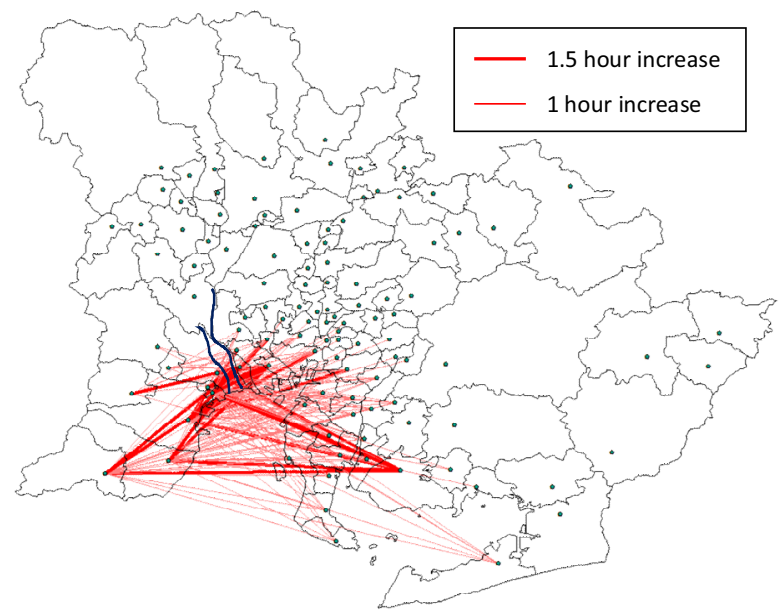

Fig. 5. Increase in traveling time

\subsection{Outcomes of scenario}

\subsubsection{Economic damage of earthquake by region and industry}

The total financial damage is calculated to be approximately 10 trillion yen/year, which constitutes $25 \%$ of GDP in the Chukyo metropolitan area.

From an industry perspective, the manufacturing, wholesale/retail and service industries are seriously damaged. The study focuses on the manufacturing industry because the purpose of this study is to analyze which factor, caused by preventing commuting or physical distribution, has the most significant effect on economic damage. Fig. 7 shows that the transport equipment industry is most seriously damaged from the manufacturing industry as there are several major car related companies (e.g., TOYOTA).

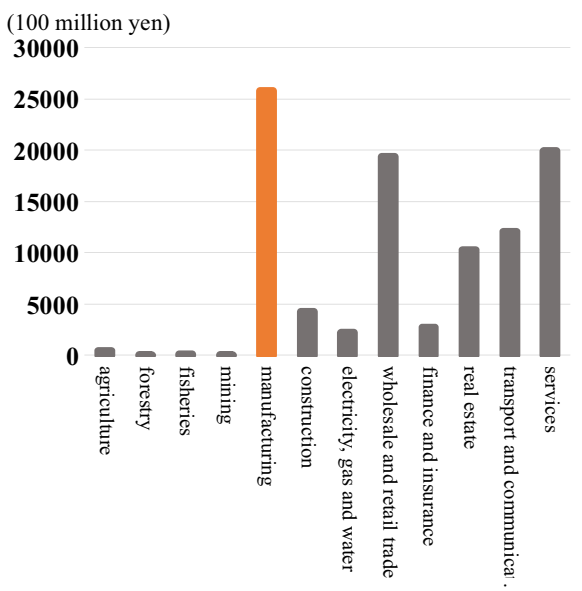

Fig. 6. Economic damage by industry

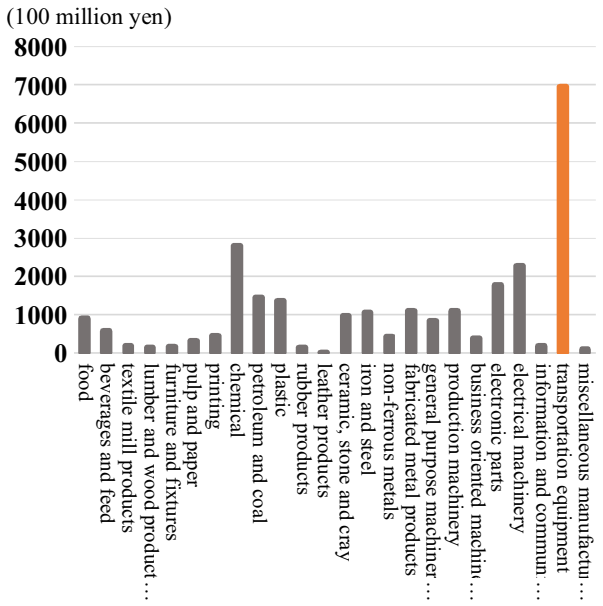

Fig. 7. Economic damage of manufacturing 


\subsubsection{Main damage factor by region (the transportation equipment industry)}

Fig. 8 shows which factor has the most significant effect on economic damage by zone. Red signifies the limited supply of labor, blue signifies the limited intermediate supply, and green signifies the limited production supply.

In the coastal areas, the limited intermediate or production supply is the main damage factor. However, in the interior area, the limited labor supply is the main damage factor. Fig. 7 shows that the traveling time increases greatly in the coastal area and an unfavorable route around the rivers needs to be taken. Thus, it is assumed that intermediate or production goods are limited.

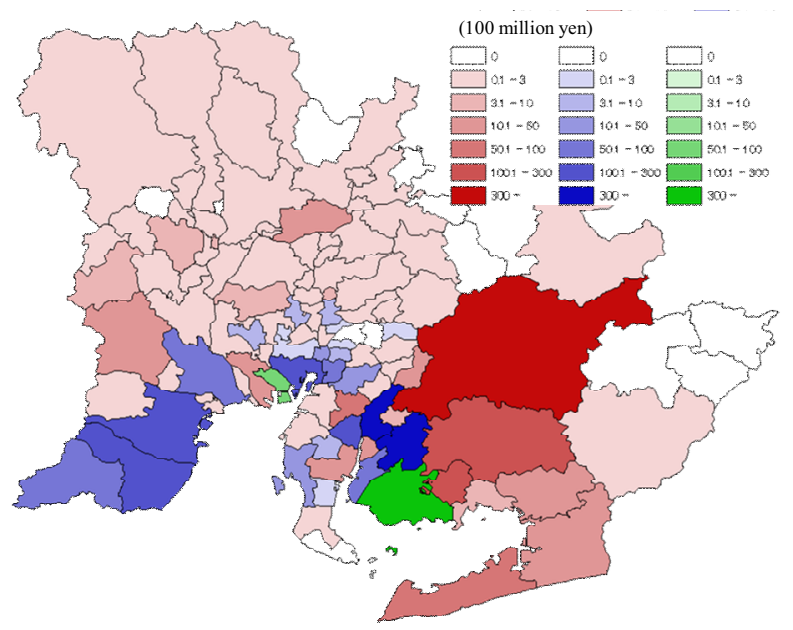

Fig. 8. Economic damage by region and the damage factor (transportation equipment industry)

\subsubsection{Effects of recovery plan for transport facilities}

We simulate two cases of transportation recovery policies in order to evaluate the effect of the economic damage reduction by the policy and propose an efficient policy.

Table 2 shows the economic damage after implementing the two transportation recovery policies. Across the whole industry, the effect of the economic damage reduction by policy 1 is about 1.1 trillion yen/year; in contrast, that of policy 2 is about 6.6 trillion yen/year. In the transport equipment industry, the effect on the recovery of the road network is much more effective than that of the railway network. This could be because railway network is only used for commuting, but road network has a multi-use (for commuting and freight transportation).

Table 2. Economic damage after each policy (100 million yen)

\begin{tabular}{|l|c|c|}
\hline & Whole industry & Transport equipment \\
\hline No recovery policies (Fig. 8) & 96,948 & 6,948 \\
\hline Recovery of railway network (Fig. 9) & 85,710 & 5,973 \\
\hline Recovery of road network (Fig. 10) & 30,665 & 1,782 \\
\hline
\end{tabular}

Fig. 9 shows the distribution of the damage factors after the recovery of the railway network. On comparing Fig. 8 and Fig. 9, we can see that the effect of the policy is not seen in regions where the main damage factor is the limitation of intermediate or production supply; although there is some effect in regions where the main damage factor is the limitation of labor supply. However, we also found that there are some regions, such as 
Inabe-shi or Tahara-shi, where the shortage of labor supply is not largely eliminated even though the railway network has recovered. A similar result is observed with policy 2 . In the coastal area, where the main damage factor is the limitation of intermediate or production supply, the economic damage due to the freight factor is largely reduced; however, there are regions such as Suzuka-shi, Nishio-shi, or Minato-ku where most of the economic damage still remains.

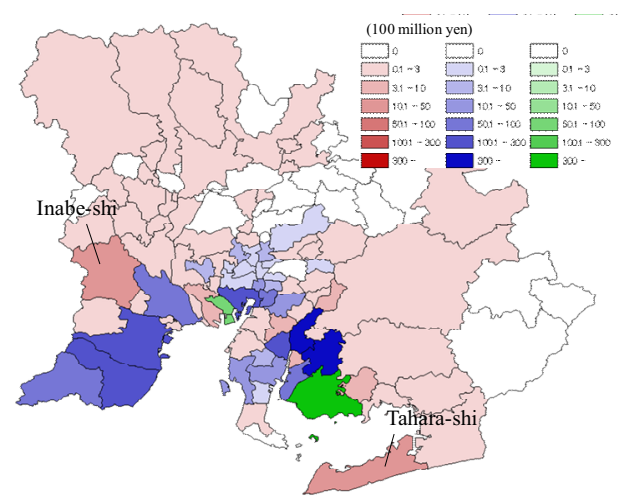

Fig. 9. Recovery of railway network

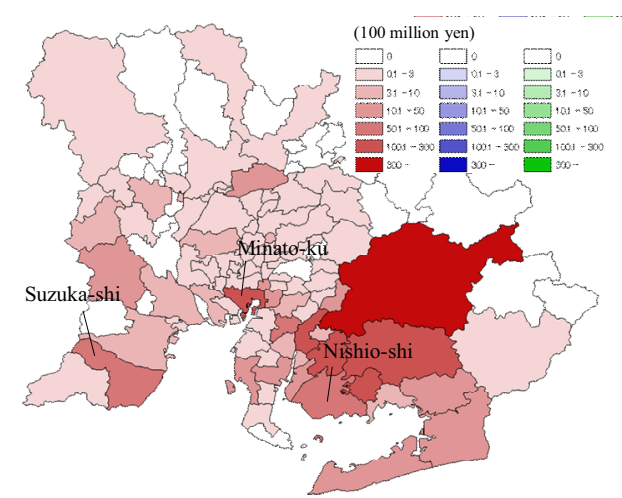

Fig. 10. Recovery of road network

\section{Conclusion}

We developed the economic damage assessment model in the short -run and applied the model to the Chukyo metropolitan area. We found the following results:

- The economic damage is mainly seen in the coastal areas where the traveling time increases largely.

- From an industry viewpoint, the transport equipment industry is most seriously damaged from the manufacturing industry.

- In the coastal areas, the limited intermediate or production supply is the main damaging factor. On the other hand, in the interior area, the limited labor supply is the main damage factor.

- The effect of the recovery of the road network is much more significant than that of the railway network.

- However, there are some regions where the effects of recovery policies are negligible even though only either one of the road network or railway network has recovered.

Thus, it is assumed that the comprehensive policy, considering the damage factor and the regional characteristics (including the development status of the transportation facilities or the industrial structure), should be planned.

\section{References}

[1] N. Hamaguchi, Result and Discussion of Survey of Disaster-hit Firms from the East Japan Quake, RIETI Policy Discussion Paper Series (2012) (in Japanese)

[2] A. Koike, T. Sasaki, Y. Sasaki, and K. Yamasaki, Evaluation of economic damage of Great East Japan Earthquake by SCGE model of municipality level, Journal of Japan Society of Civil Engineers, Ser. D3, 70(5), 151-159 (2014) (in Japanese)

[3] S. Tsuchiya, Y. Tatano, and N. Okada, A framework of measuring economic losses from the Niigata-Chuetsu earthquake, Journal of Japan Society of Civil Engineers, Ser. D3, No. 23, No. 2 (2006) (in Japanese) 